\title{
EL AMPARO COLECTIVO Y EL SISTEMA REGISTRAL DE LAS ACCIONES COLECTIVAS: A UN LUSTRO DE LAS ACORDADAS 32/2014 Y 12/2016 DE LA CoRte Suprema de Justicia de la NacióN
}

\section{Marcela Sandra Molina}

Universidad Católica Argentina (sede Mendoza)

marcsmolina@yahoo.com.ar

Recibido: 10/04/2021

Aceptado: 28/04/2021

\section{Resumen}

La inexistencia de una regulación general nacional del amparo y de las acciones colectivas genera inseguridad jurídica en su tramitación (como la litispendencia y el riesgo de proliferación de procesos con idéntico objeto en distintas jurisdicciones). Ello exige sistemas de publicidad idóneos, especialmente registrales, para la identificación de los procesos colectivos en trámite en todo el ámbito nacional, como así también la imposición de nuevos deberes al órgano judicial y a abogados. Esta necesidad es aún mayor en los amparos colectivos, por tratarse de una garantía constitucional que debe tramitar a través de un proceso rápido y expedito para restablecer el derecho vulnerado. La organización y funcionamiento del registro debe guiarse por principios que aseguren el cumplimiento de su finalidad.

En definitiva, este artículo resalta la importancia y necesidad de los sistemas registrales de las acciones colectivas, analizando los sistemas existentes en el derecho comparado y en Argentina, sus fallas y omisiones.

Palabras clave: amparo colectivo, acciones de clase, acciones colectivas, registro de acciones colectivas. 


\title{
Collective Constitutional Actions and the Registry of Class Actions: Five Years Since Argentine Supreme Court Rules 32/2014 and 12/2016
}

\begin{abstract}
The absence of class actions' federal legislation creates legal uncertainty (especially the risk of overlapping processes with cause and object identity). This requires adequate information systems to identify pending collective processes at the national level as well as the imposition of new duties on the judges and lawyers. This need is greater in constitutional actions that must be quick and expeditious to re-establish the rights that have been violated. The organization of the registry must be guided by principles that ensure the fulfillment of its purpose.

Specifically, this article highlights the importance and necessity of the registration publicity systems, analyzing the existing systems in comparative law and in our country; its faults and omissions.
\end{abstract}

Key words: constitutional processes, class actions, class actions registry.

\section{Introducción}

El artículo 43 de la Constitución Nacional (en adelante, CN), reformada en 1994, prevé una acción judicial rápida y expedita como garantía de los derechos fundamentales, entre ellos, los derechos de incidencia colectiva.

El Congreso Nacional no ha reglamentado la acción de amparo colectivo, ni siquiera las acciones colectivas en general, aun cuando se han presentado numerosos proyectos de ley con distinto alcance y legitimación. Algunos han buscado receptar la acción de clase, y otros, una acción colectiva amplia. Solamente se han introducido algunas normas procesales escuetas en las Leyes 24240 y 25675 (cuyo artículo 30 establece una legitimación muy amplia y prevé expresamente el amparo ambiental).

Hay distintas opiniones doctrinarias sobre la consagración expresa de la garantía de amparo colectivo en el artículo 43, párrafo 2 de la CN. Algunos sostienen que hay una consagración expresa, ${ }^{1}$ mientras que otros consideran que el texto constitucional prevé el amparo en general. ${ }^{2}$ Lo cierto es que la acción de amparo mencionada en el primer párrafo del artículo 43 no se adapta al amparo colectivo, dejando amplios vacíos normativos en torno a numerosos aspectos procesales (legitimación, identificación y delimitación del grupo, cer-

1 Ver Basterra (2013, p. 1232); Bidart Campos (2004, p. 212); Gelli (2004, p. 396); López Alfonsín et al. (2018, p. 28).

2 Se trata del amparo "con independencia de la ampliación de los sujetos legitimados procesalmente para su promoción, conclusión a la que lleva el propio texto del $2^{\circ}$ párr. del art. 43 cuando alude a esta acción” (Olmos Sonntag, 2016, pp. 201-202). 
tificación del grupo, publicidad, litispendencia, competencia, atracción de procesos y acumulación, sustanciación de la prueba, admisión de otros legitimados y de terceros coadyuvantes, disponibilidad de la acción, efectos de la sentencia, cosa juzgada, terminación anormal del proceso) y otros aspectos instrumentales y organizacionales (creación de registros de procesos colectivos, colaboración recíproca y comunicación permanente entre esos registros, la imposición de nuevos deberes a los jueces, etc.).

La regulación de la acción de amparo colectivo y, en general, de todas las acciones colectivas es una necesidad impostergable. En el período 2014-2017 se tramitaron 927 procesos colectivos en el fuero federal (Verbic, 2017). Esta cantidad parece ínfima en comparación con el número total de procesos que ingresan por año en cada fuero. Sin embargo, más allá del aspecto cuantitativo, lo que más resalta en estos procesos es su complejidad, la pluralidad de titulares y legitimados (algunos extraordinarios), el conflicto de múltiples intereses, sus efectos erga omnes y, en muchos casos, su importancia institucional.

La inexistencia de una regulación sistemática en el ámbito federal genera inseguridad jurídica en su tramitación y riesgo de proliferación de procesos con idéntico objeto en distintas jurisdicciones. Este riesgo exige sistemas de publicidad para la identificación de las acciones colectivas, en particular la creación de un registro para evitar el escándalo jurídico que producirían sentencias contradictorias con efectos expansivos. Esta necesidad es aún mayor en los amparos colectivos, por la exigencia constitucional de erigirse en una vía expedita y rápida.

Ante la omisión del legislador, la Corte Suprema de Justicia de la Nación (en adelante, CSJN), mediante la Acordada 32/2014, ha creado un Registro Público de Procesos Colectivos en el ámbito del Poder Judicial de la Nación.

Esta omisión contrasta con el derecho público provincial, dado que el amparo colectivo fue receptado por algunas constituciones provinciales antes de la reforma de la CN de 1994 y fue regulado por las legislaturas de varias provincias. Estas normas provinciales se adelantaron al legislador nacional, plasmando reglas para dar solución a distintos conflictos que se fueron planteando.

La Constitución Nacional y las constituciones provinciales receptan una legitimación amplia del amparo colectivo. Por eso hay que reglamentarlo y organizarlo, para evitar una alta litigiosidad, la desvirtuación de esta garantía constitucional, el desgaste jurisdiccional y la proliferación de juicios idénticos que pueden terminar con sentencias contradictorias con efectos expansivos. ${ }^{3}$

3 Los procesos colectivos plantean una serie de cuestiones. Primero, la tipicidad: derechos de incidencia colectiva (indivisible) y derechos individuales homogéneos (eficiencia, economía procesal). Se- 
En el presente estudio, partimos de una visión integral del amparo colectivo que comprende aspectos constitucionales (en tanto garantía consagrada en la $\mathrm{CN}$, distribución de poder nación-provincias) y aspectos comunes a las acciones colectivas, ya sea procesales (requisitos de la demanda, certificación de clase, legitimación, litispendencia, conflictos de competencia) o administrativos (organización de registros de acciones colectivas, etc.).

Nos referiremos a los medios y vías para evitar la proliferación de amparos colectivos con identidad de objeto y causa. Especialmente destacamos la importancia y necesidad del sistema registral de las acciones colectivas que prevea una categorización según clase de acciones y tipo de proceso. Todo ello, para facilitar la identificación de conflictos de competencia, litispendencia, conexidad, analizando los sistemas existentes en el derecho comparado y en nuestro país, sus fallas, omisiones, sus efectos y alcances.

\section{Las acciones colectivas y los sistemas de publicidad}

a) Los autores mencionan como antecedente el Bill of Peace del derecho anglosajón (siglo XVII) (Bianchi, 1998, pp. 10-30; Carnota, 2012; Salgado, 2010) y las class actions de Estados Unidos (siendo sus antecedentes: Equity Rule 48 de $1842^{4}$ y Equity Rule 38 de 1912).

En 1938, se dictó la Rule 23 -modificada en 1966-, que estableció requisitos de procedencia, entre los cuales menciona el riesgo de sentencias contradictorias. ${ }^{5}$ El juez norteamericano tiene la facultad de evaluar si en el caso concreto se ha cumplido o no el requisito, atendiendo a sus circunstancias particulares. En caso afirmativo, certifica la clase (aprobación de la calificación y tratamiento como una acción de clase) (Bianchi, 1998). En el año 2005, se dictó la Class Ac-

gundo, la legitimación. En Estados Unidos, class actions sigue la lógica del mercado. En otros países, la legitimación está concentrada en el sector público (Europa y Brasil). En Argentina, son sujetos legitimados: el afectado, asociaciones (ONG), sector público (Defensor del Pueblo, fiscales). Las estadísticas muestran litigiosidad innecesaria. Este jurista considera positiva la amplia legitimación, pero sostiene que hay que organizarlo y buscar un equilibrio, sugiriendo una visión amplia de estas acciones (Lorenzetti, 2012).

4 Sobre las class actions en el derecho norteamericano, ver Bianchi (2003); Salgado (2010); Vergara (2011).

5 "Rule 23: (1) the class is so numerous that joinder of all members is impracticable; (2) there are questions of law or fact common to the class; (3) the claims or defenses of the representative parties are typical of the claims or defenses of the class; and (4) the representative parties will fairly and adequately protect the interests of the class. (b) Types of Class Actions...”. Disponible en: https:// www.law.cornell.edu/rules/frcp/rule_23. Al respecto, ver Gidi (2004). 
tion Fairness Act, ${ }^{6}$ que mejoró el procedimiento y confirió competencia federal en las grandes demandas colectivas. ${ }^{\text {? }}$

Un aspecto relevante es que el Federal Judicial Center (JFC) lleva una base de datos digital ${ }^{8}$ y de acceso público, que centraliza la información de todos los procesos desde 1970, indicando tipo y materia (no está limitado a las acciones de clase), objeto, partes, fecha de inicio y terminación. El abogado es quien debe investigar la existencia de procesos pendientes con idéntico objeto. ${ }^{9}$

Por su parte, la Federal Trade Commission tiene a su cargo la protección de los consumidores y de la competencia, mediante la prevención de prácticas comerciales desleales, engañosas y anticompetitivas a través de la promoción y la educación. Además, lleva un registro con mención de datos relevantes (fecha de inicio y estado procesal, partes, descripción de los hechos, tribunal, número de expediente, actos procesales y documentación). ${ }^{10}$

Esta base de datos con finalidad informativa y estadística difiere del registro de acciones de clase que llevan otros países que siguen el sistema del common law, como Australia, ${ }^{11}$ donde los registros proveen información de las causas judiciales detallando los actos procesales relevantes.

b) En Canadá, el primer antecedente normativo sobre las acciones colectivas se encuentra en el Código de Procedimiento Civil de Quebec, ${ }^{12}$ que previó normas para las class actions en 1978 (artículos 571 a 604). En Ontario, el debate de un proyecto comenzó en 1982, tomando el modelo norteamericano. En 1992 se aprobó un moderno estatuto sobre procedimiento de las class actions.

6 Sancionada el 28/02/2005.

7 "SEC. 2. - Congress finds the following: (1) Class action lawsuits are an important and valuable part of the legal system when they permit the fair and efficient resolution of legitimate claims of numerous parties by allowing the claims to be aggregated into a single action against a defendant that has allegedly caused harm. (2) Over the past decade, there have been abuses of the class action device that have: A) harmed class members with legitimate claims and defendants that have acted responsibly; B) adversely affected interstate commerce; C) undermined public...”.

8 La Junta Directiva del Federal Judicial Center es presidida por el presidente del Tribunal Supremo. Disponible en: https://www.fjc.gov/research/idb/civil-cases-filed-terminated-and-pending-sy-1988-present.

9 En Estados Unidos, el sistema de las class actions sigue la lógica del mercado (riesgos-beneficios, inversión) (Lorenzetti, 2012).

10 Federal Trade Commission. Disponible en: https://www.ftc.gov/about-ftc.

11 Federal Court of Australia. Disponible en: https://www.fedcourt.gov.au.

12 Quebec es una jurisdicción de derecho civil que se rige por un código civil formal, con una fuerte influencia del sistema legal civil francés. Las demás provincias canadienses tienen un derecho sustantivo que combina la legislación federal, la legislación provincial y el derecho consuetudinario elaborado por jueces, siguiendo la tradición jurídica británica. 
Marcela Sandra Molina | El amparo colectivo y el sistema registral de las acciones colectivas: a un lustro de las acordadas 32/2014 y 12/2016 ...

Posteriormente, las demás provincias sancionaron sucesivamente su legislación sobre las class actions (Rosenberg, 2016), excepto en Prince Edward Island (aunque recientemente fue acogida por un fallo del Máximo Tribunal de esa Provincia). ${ }^{13}$ En el año 2002, se introdujo una enmienda al Reglamento del Tribunal Federal, en la que se aprobó una regulación para los procesos colectivos.

La Asociación de Colegios de Abogados Canadiense provee una base de datos nacional de acciones colectivas de fácil acceso con documentos judiciales de todo el país, pero es incompleta, ya que es una iniciativa voluntaria.

Solamente la provincia de Quebec tiene un registro digital de class actions, ${ }^{14}$ que proporciona información de aquellas presentadas desde el 1 de enero de 2009. Este registro permite el acceso a la documentación indispensable para conocer la delimitación de la clase (admisión, defensa del demandado, resoluciones judiciales).

c) En Brasil, los antecedentes se remontan a 1977, con la sanción de la Ley de Acción Popular. Poco después, la Constitución de 1988 (artículo 5) previó el amparo colectivo y la acción popular.

El derecho brasilero recepta la siguiente clasificación: a) derechos difusos (indivisibles, pertenecen a personas indeterminadas vinculadas por un hecho común); b) derechos colectivos (indivisibles, pertenecen a un grupo de personas ligadas por una relación jurídica común); y c) derechos individuales homogéneos. ${ }^{15}$ Por su parte, la Ley $8078^{16}$ otorga legitimación al Ministerio Público, a los Gobiernos estatales, municipales y federal, a la administración pública y a las asociaciones cuyo objeto sea la protección de derechos colectivos. Carecen de legitimación las personas físicas, por tanto, el riesgo de superposición de procesos con idéntico objeto disminuye.

Un aspecto importante es que el artículo 44 de esa ley prevé un catastro público de acceso libre, en el que se asientan las reclamaciones fundamentadas en contra de proveedores de productos y servicios, debiendo informar, entre otras cosas, si la reclamación fue atendida o no por el proveedor.

13 La Corte de Apelaciones dijo: "... a los residentes no se les debe negar un esquema legislativo moderno e integral en el cual litigar sus reclamos”, King $\mathcal{E}$ Dawson v. el Gobierno de P.E.I, 2020.

14 Disponible en: https://www.registredesactionscollectives.quebec/.

15 Dinier y Zaneti (2017) explican que el enjuiciamiento de casos repetitivos tiene por objeto la definición sobre cuál es la solución que ha de darse a una cuestión jurídica (procesal o material, individual o colectiva). "Esos procesos pueden ser homogéneos (tienen por objeto litigioso una cuestión de derecho similar) o heterogéneos (tiene un objeto litigioso diferente, pero hay cuestiones comunes, normalmente procesales, que se repiten en todos ellos" (p. 271).

16 Sancionada el 11/09/1990, D.O. 176, 09/12/1990. 
En septiembre de 2020, el Consejo Nacional de Justicia de Brasil presentó un anteproyecto de Ley de Acciones Colectivas, que prevé un catastro público para todas las acciones colectivas.

d) En España, la Ley $1 / 2000^{17}$ reguló aspectos procesales de las acciones colectivas (legitimación, determinación de los miembros del grupo, formas de comunicación de la existencia del proceso, efectos de la sentencia, ejecución de sentencias) (Neira Pena, 2019, pp. 196 y 218).

La legislación española tiene aspectos relevantes. Primero, prevé la legitimación del Ministerio Fiscal y de las asociaciones de consumidores anotadas en el registro respectivo. Los afectados tienen legitimación si sus miembros están determinados o son determinables y siempre que se presenten en juicio la mayoría de ellos. Segundo, autoriza la acumulación de procesos individuales con el mismo objeto, aun de oficio. Tercero, regula los efectos de la sentencia para las partes y miembros del grupo no litigantes.

e) En Colombia, la Ley $472^{18}$ reguló la acción popular y las acciones de clase conforme lo dispuesto en la Constitución de 1991 (artículos 88 y 89) (Guayacán Ortiz, 2005, pp. 35-56). El artículo 12 de la ley confiere legitimación a toda persona física o jurídica, a organizaciones no gubernamentales, a entidades públicas, al procurador general, al defensor del pueblo y a personeros locales, alcaldes y servidores públicos. Para su procedencia debe acreditarse: 1) grupo de al menos veinte personas; 2) pertenencia a un grupo; y 3) condiciones uniformes del perjuicio.

La ley colombiana ha creado un registro de carácter público dentro del ámbito de la Defensoría del Pueblo, que centraliza información de las acciones populares y las acciones de grupo, proveyendo datos sobre el proceso (número, carátula, tribunal), objeto, partes, descripción de los hechos, fecha de inicio y terminación y actos procesales relevantes.

\section{El amparo colectivo en el ámbito nacional}

\subsection{El artículo 43 de la Constitución Nacional reformada en 1994}

El segundo párrafo del artículo 43 de la Constitución Nacional dispone:

... Podrán interponer esta acción contra cualquier forma de discriminación y en lo relativo a los derechos que protegen al ambiente, a la competencia, al usuario

17 Sancionada el 07/01/2000, B.O.E. 7, 08/01/2000.

18 Sancionada 05/08/1998, D.O. 43357, 06/08/1998. 
y al consumidor, así como a los derechos de incidencia colectiva en general, el afectado, el defensor del pueblo y las asociaciones que propendan a esos fines, registrados conforme a la ley, la que determinará los requisitos y formas de organización...

Hay distintas posturas doctrinarias sobre la interpretación del artículo 43 párrafo 2 de la CN, particularmente sobre la incorporación expresa del amparo colectivo (Quiroga Lavié, 2012) y la inclusión del amparo ambiental (Basterra, 2013). Otros consideran que el texto constitucional prevé el amparo en general (Olmos Sonntag, 2016).

Hay tres aspectos fundamentales del texto constitucional reformado:

Primero, el amparo colectivo es una especie dentro del género amparo, esto es, una garantía constitucional en tanto es un medio para hacer efectivo y real el restablecimiento de un derecho fundamental vulnerado, exigiendo un trámite procesal expedito, simple y rápido. ${ }^{19}$ Este criterio ha sido recogido por los tribunales superiores de las provincias. ${ }^{20}$

Segundo, las normas legales deben prever un ámbito de aplicación amplio y comprensivo de todos los derechos de incidencia colectiva, no solo los derechos enumerados en los artículos 41, 42 y 43, segundo párrafo, sino también en los tratados internacionales de derechos humanos.

Tercero, entre los sujetos legitimados, además del Defensor del Pueblo y de las asociaciones civiles, el artículo 43 le confiere legitimación al mismo afectado. Esta amplia legitimación requiere ser canalizada adecuadamente y organizada (Lorenzetti, 2012).

El régimen jurídico del amparo regulado por la Ley 16986 no se adapta a la naturaleza colectiva del amparo colectivo, quedando amplios vacíos normativos en torno a numerosos aspectos procesales. Por eso, deben regularse todas las cuestiones que generan conflictos sin perder de vista la agilidad y sencillez propias de esta garantía constitucional.

Insistimos que, hasta fines de 2019, el amparo colectivo no había sido reglamentado en el ámbito nacional y tampoco las acciones colectivas en general, a pesar de la presentación de numerosos proyectos de ley en el Congreso de la Nación y de anteproyectos elaborados por juristas, como aquel de Quiroga La-

19 Corte Suprema de Justicia de la Nación, Portal de Belén Asoc. Civil c/Ministerio de Salud de la Nación, 05/03/2002, Fallos: 325:292.

20 Suprema Corte de Justicia de Mendoza, Egea c/Dirección de Vías y Medios de Transporte, 07/02/2011, LS. $422,157$. 
vié (1996, p. 1057). En la Cámara de Diputados se han presentado 16 proyectos que establecen un régimen general del amparo (incluye el amparo colectivo), ${ }^{21}$ siendo el último uno presentado en el mes de septiembre de $2019 .{ }^{22}$

Todos estos proyectos de ley inspirados en distintas fuentes presentan profundas diferencias en cuanto al alcance (algunos solo incluyen los derechos colectivos; otros, los derechos individuales homogéneos o ambos) y criterio normativo (algunos regulan el amparo colectivo dentro de una ley general de amparo; otros, dentro de un régimen general de acciones colectivas).

Puede advertirse, entonces, que la sanción de la ley exige un debate previo sobre el tipo de acciones colectivas que se intenta regular (una acción popular o acciones de clase) y sus fuentes, cuyo análisis excede el objeto del presente trabajo.

Cualquiera sea la motivación de esta dilatada demora, lo cierto es que la inexistencia de regulación nacional afecta la seguridad jurídica, paliada en parte por la jurisprudencia y acordadas de la CSJN, aplaudida por un amplio sector doctrinario ${ }^{23}$ y criticada por otros (Sagües, 2016). Entre los casos jurisprudenciales, destacamos: Asociación Benghalensis, ${ }^{24}$ Mendoza, ${ }^{25}$ Defensor del Pueblo, ${ }^{26}$ Pla ${ }^{27}$ Halabi, ${ }^{28}$ PADEC ${ }^{29}$ y Municipalidad de Berazategui. ${ }^{30}$

\subsection{La jurisprudencia de la CSJN: el fallo in re Halabi}

Este fallo presenta varios aspectos relevantes. Primero, siguió la postura amplia que incluye dentro de la noción de "derechos de incidencia colectiva" a los de-

21 Disponible en: https://www.diputados.gov.ar/proyectos/index.html.

22 Expediente 4326-D-2019, presentado el 12/09/2019. Honorable Cámara de Diputados de la Nación.

23 "... frente a la omisión permanente de los poderes políticos de cumplir con sus concretas obligaciones constitucionales [...] Felicitaciones Corte Suprema de los argentinos" (Quiroga Lavié, 2012. pp. 169-181).

24 Corte Suprema de Justicia de la Nación, Asociación Benghalensis c/Ministerio de Salud de la Nación, 01/06/2000, Fallos: 323:1339.

25 Corte Suprema de Justicia de la Nación, Mendoza, Beatriz c/Estado Nacional, 30/08/2006, Fallos: 329:3528. También, Mendoza, Beatriz c/Estado Nacional, 20/06/2006 Fallos: 329:2316.

26 Corte Suprema de Justicia de la Nación, Defensor del Pueblo de la Nación c/Estado Nacional, 26/07/2007, Fallos: 330:2800.

27 Corte Suprema de Justicia de la Nación, Pla, Hugo c/Provincia de Chubut, 13/05/2008, Fallos: 331:1243.

28 Corte Suprema de Justicia de la Nación, Halabi, Ernesto, 04/03/2009, Fallos: 332:111.

29 Corte Suprema de Justicia de la Nación, PADEC c/SWISS MEDICAL S.A., 21/08/2013, Fallos: $336: 1236$.

30 Corte Suprema de Justicia de la Nación, Municipalidad de Berazategui c/Cablevisión S.A., 23/09/2014, Fallos: 337:1024. 
rechos individuales homogéneos (aquellos en los que existe un hecho, único o continuado, que provoca la lesión a todos ellos, con una homogeneidad fáctica y normativa).

Segundo, declaró la operatividad del artículo 43 de la CN. En este sentido, dijo: "... donde hay un derecho hay un remedio legal para hacerlo valer toda vez que sea desconocido...".

Tercero, mencionó como los presupuestos: 1) causa fáctica común; 2) pretensión colectiva; y 3) constatación de que el ejercicio individual no aparece justificado, existiendo un interés estatal en su protección, sea por su trascendencia social o por las características de los sectores afectados. Por su parte, como recaudos de la demanda: 1) identificación del grupo; y 2) idoneidad de la representación.

Cuarto, se expidió sobre los efectos erga omnes de la sentencia y otros temas procesales.

Quinto, resaltó la necesidad de implementar medidas de publicidad orientadas a evitar la multiplicación de procesos colectivos con un mismo objeto, "a fin de aventar el peligro de que se dicten sentencias disímiles o contradictorias sobre idénticos puntos" (considerando 20 del fallo).

\subsection{El fallo de la CSJN in re Municipalidad de Berazategui}

En esta causa judicial, el intendente de Berazategui había promovido una acción en defensa de los derechos de incidencia colectiva del conjunto de usuarios del servicio de televisión por cable de ese partido, con el fin de que se condene a la empresa demandada a cumplir con resoluciones de la Secretaría de Comercio Interior.

La CSJN dijo en ese fallo:

Teniendo en cuenta que se ha advertido un incremento de causas colectivas con idénticos o similares objetos que provienen de distintos tribunales del país, lo que genera, además de un dispendio jurisdiccional, el riesgo cierto de que se dicten sentencias contradictorias y de que las decisiones que recaigan en uno de los procesos hagan cosa juzgada respecto de las planteadas en otro [...] se estima necesaria la creación de un Registro de Acciones Colectivas -a través de una acordada- en tanto los aludidos inconvenientes podrían conllevar a situaciones de gravedad institucional. 
El máximo Tribunal ha continuado advirtiendo la superposición de procesos con identidad de objeto, causa y sujetos en posteriores sentencias (entre ellas, Consumidores Financieros c/La Meridional Compañia de Seguros ${ }^{31}$ y Consumidores Financieros c/Banco Itaú ${ }^{32}$ ) y ha continuado exhortado a los tribunales de grado a implementar adecuadas medidas de publicidad orientadas a evitar la superposición, ya sea imponiendo a la actora el deber de informar en su primera presentación procesal si ha iniciado más de un proceso colectivo con idéntico objeto o por otros mecanismos de información y publicidad.

\section{Sistemas de publicidad registral de las acciones colectivas}

El amparo colectivo es una garantía constitucional que protege los derechos de incidencia colectiva, cuyos titulares pueden estar dispersos en toda la provincia, en varias provincias o en todo el país.

En realidad, existe el riesgo de multiplicación de distintos tipos de procesos con identidad de objeto y causa radicados en distintas jurisdicciones -entre ellos, amparos colectivos-, generando conflictos de competencia y potencialmente sentencias contradictorias con efectos erga omnes. La amplia legitimación reconocida en el artículo 43 de la $\mathrm{CN}$ y la inexistencia de una regulación de las acciones colectivas por el Congreso de la Nación acrecienta ese riesgo.

Esta situación exige un sistema de publicidad adecuado para la litispendencia o conexidad de procesos ante otros tribunales provinciales o ante el Poder Judicial de la Nación, y también requiere la imposición de nuevos deberes a los jueces, auxiliares de justicia y abogados.

Debemos tener en cuenta que, en general, un sistema de publicidad tiene por objeto hacer cognoscible un hecho, una situación o una relación jurídica o procesal. El fundamento de estos sistemas de publicidad es la seguridad jurídica.

Hay distintos medios de publicidad según la finalidad y la naturaleza de los hechos o relación jurídica que se pretende dar a conocer (relaciones comerciales, situaciones jurídicas reales o procesos judiciales). Estos sistemas pueden ser registrales o no registrales.

El sistema de publicidad registral funciona desde hace varias décadas para

31 Corte Suprema de Justicia de la Nación, Consumidores Financieros c/La Meridional Cía de Seguros, 24/06/2014, Fallos: 337:762.

32 Corte Suprema de Justicia de la Nación, Consumidores Financieros c/Banco Itaú Buen Ayre Argentina, 24/06/2014, Fallos: 337:753; también, Consumidores Financieros c/Banco Itaú Buen Ayre Argentina, 10/07/2018, Fallos: 341:739. 
Marcela Sandra Molina | El amparo colectivo y el sistema registral de las acciones colectivas: a un lustro de las acordadas 32/2014 y 12/2016 ...

el régimen inmobiliario, automotor, propiedad intelectual, mercado de valores, actos de última voluntad, etc. En estos últimos, hay un amplio marco legislativo y reglamentario que regulan distintos aspectos de su organización y funcionamiento.

El registro no es una mera base de datos (conjunto sistematizado de datos con finalidad meramente informativa), sino una institución con fines de dar publicidad formal a determinados hechos, circunstancias o derechos, que funciona bajo regulación y control de la Administración para dar seguridad jurídica. Esta publicidad produce efectos jurídicos.

Los sistemas de publicidad registral no son ajenos ni desconocidos en el ámbito procesal. En efecto, en el ámbito del Poder Judicial nacional y provinciales funcionan registros de distinta índole: de procesos universales, de deudores alimentarios, de adopción, de detenidos y, en algunas provincias, el registro de delitos contra la administración pública.

El sistema de publicidad de las acciones colectivas ha ido imponiéndose en el derecho comparado en la última década. Ya mencionamos algunas legislaciones extranjeras que han creado registros especiales en los últimos diez o quince años, como la legislación de Colombia (para acciones populares y acciones de clase), la de Canadá (Quebec) y la de Australia para acciones de clase, etc.

En nuestro país, la doctrina venía bregando por la necesidad de un registro de acciones colectivas (Falcón, 2007, p. 972; Gauffin, 2015; Timpanaro, 2012, pp. 294-295). Algunos autores destacan su importancia no solo como mecanismo de información, sino también de seguimiento (Gozaíni, 2014).

Es importante resaltar que la publicidad de las acciones colectivas, en general, se efectúa por medio de edictos o de comunicación social (radio, televisión, periódicos) y digital (página de internet de la demandada ${ }^{33}$ o del Poder Judicial, publicidad en redes sociales). ${ }^{34}$ Algunos autores proponen los mensajes de texto o correos electrónicos masivos, o colocación de cartelería en lugares visibles dentro de los locales de la parte demandada (Verbic, 2015). Estos sistemas de

33 “... la carga impuesta a la aseguradora se cumplirá [...] con la retransmisión del contenido de la información en un banner destacado de su página web" (Cámara Nacional Comercial, sala F, Consumidores Financieros Asociación Civil c/Liderar Compañia de Seguros SA, 22/08/2013). Ha seguido un criterio similar la Cámara Comercial, sala D, en PROCONSUMER c/LAN Argentina SA s/sumarísimo, $12 / 12 / 2017$.

34 “... corresponde notificar por medio de un 'banner' en la página web de la demandada y a través de 'Facebook' y/o redes sociales y/o medio digitales de gran alcance la existencia del proceso..." (Cámara Comercial, sala C, ASOCIACIÓN PROTECCIÔN CONSUMIDORES DEL MERCADO COMUN DEL SUR-PROCONSUMER c/COTO SA, 06/11/2019). 
publicidad pretenden poner en conocimiento y garantizarles a los interesados el ejercicio de sus derechos; además, informan a la sociedad. ${ }^{35}$

Ahora bien, los hechos demostraron que estos sistemas son insuficientes, pues es necesario identificar los procesos con identidad de objeto y causa, concentrar procesos conexos ante un mismo juez, acumular, etc. Esa última es la finalidad del sistema registral, en el cual la publicidad se efectúa a través de un registro en el que se asienta el hecho, situación o relación jurídica que se quiere dar a conocer.

Lo cierto es que hay cuestiones constitucionales, procesales, administrativas y técnico-registrales que inciden en la organización de este registro. Entre las procesales, se encuentra la amplitud de la legitimación anómala y la naturaleza de la acción (¿acción popular o acción de clase?), cuya regulación y alcance difiere en la legislación nacional y provincial.

En el aspecto constitucional, debe tenerse en cuenta la naturaleza constitucional del amparo colectivo; la distribución de poderes en la nación-provincias establecido en la CN en los artículos 121, 122, 123 y concordantes.

En cuanto a los aspectos administrativos, implica: optar por una forma centralizada o desconcentrada; determinar el órgano u órbita dentro del cual se crea y de quién depende dentro de la estructura administrativa (Poder Judicial, Legislativo o Ejecutivo); delimitar su competencia; establecer el tipo de soporte del registro (material o digital); disponer la forma y plazos de las comunicaciones del órgano judicial, la forma de la consulta por los abogados, etc.

Finalmente, debe tenerse en cuenta aspectos técnicos-registrales: establecer el tipo y contenido de los asientos registrales (según los sujetos y la carátula o causa), los efectos de la anotación y la validez de los informes registrales.

\subsection{El registro nacional de procesos colectivos: Ias Acordadas 32/2014 y 12/2016}

Al poco tiempo de dictar la sentencia en la causa judicial Municipalidad de Berazategui, y hasta tanto el Congreso Nacional dicte una norma regulatoria de las acciones colectivas, el superior tribunal emitió la Acordada 32/2014, invocando las facultades reglamentarias conferidas por el artículo 4, segundo párrafo de la Ley 25488, por el artículo 18 de la Ley 48 y por el artículo 10 de

35 “... la interposición de la demanda, la apertura de la instancia, la traba de la litis, el debate y decisión deberán ser debidamente publicitadas a fin de garantizar la posibilidad de que todos aquellos que estén interesados puedan ejercer los derechos [...] procura informar a la sociedad toda acerca de la existencia y evolución de este tipo de procesos" (Giannini et al., 2016). 
Marcela Sandra Molina | El amparo colectivo y el sistema registral de las acciones colectivas: a un lustro de las acordadas 32/2014 y 12/2016 ...

la Ley 4055. El máximo tribunal tiene potestad de dictar reglamentos internos conforme el artículo 113 de la $\mathrm{CN}$, quedando incluidas las cuestiones sobre el funcionamiento y administración de justicia en tanto no modifiquen o alteren las normas del Código Procesal.

Mediante esta norma, creó el Registro Público de Procesos Colectivos, radicado ante tribunales del Poder Judicial de la Nación, con carácter público, gratuito y de acceso libre, e invitó a los superiores tribunales provinciales y de la Ciudad Autónoma de Buenos Aires a suscribir convenios con la Corte nacional para compartir la información y facilitar el acceso recíproco e ilimitado a los registros respectivos.

Esta Acordada consagra una serie de reglas que pueden sintetizarse en los principios de registración única, publicidad y prevención.

El artículo 1 del Reglamento receptó un criterio amplio y abarcativo, estableciendo la obligatoriedad del registro de todos los procesos colectivos, tanto los que tengan por objeto bienes colectivos como los que promuevan la tutela de intereses individuales homogéneos con arreglo a las definiciones dadas por esta Corte en los precedentes Halabi y PADEC c/Swiss Medical S.A, radicados ante el Poder Judicial de la Nación, cualquiera que fuese la vía procesal por la cual tramiten -juicio ordinario, amparo, hábeas corpus, hábeas data u otros- y el fuero ante el que estuvieran radicados.

Sin embargo, poco después, la Acordada 12/2016 excluyó los procesos que se inicien en los términos de la Ley 25675, los cuales se rigen por esa norma. Tampoco se aplica este a los procesos colectivos que involucren derechos de personas privadas de la libertad y procesos penales.

Esta Acordada 12/2016 detalló el trámite preliminar de pedidos de informes al Registro, la primera providencia del juez que declara provisoriamente el carácter colectivo del proceso, su anotación en el registro y posteriores resoluciones que se dicten.

Estos registros están organizados sobre la base de los siguientes pilares:

- Principio de registro único. El deber impuesto a los jueces de comunicar al Registro la resolución judicial que califica una acción como colectiva para su anotación, informando el tipo de proceso y los actos procesales posteriores. Una vez registrado, no podrá registrarse otro que presente una sustancial semejanza.

- Principio de prevención. Algunos autores agregan el principio de atracción (Palacio de Caeiro y Junyent de Dutari, 2016, p. 703). La Acordada 12/2016 prevé que si del informe extendido por el encargado del Registro surge la 
existencia de una causa judicial en trámite, registrada con anterioridad y que presente una sustancial semejanza en la afectación de los derechos de incidencia colectiva, el magistrado requirente deberá remitir el expediente al juez que previno, salvo que el juez interviniente, mediante resolución fundada, desestime la prevención y atracción por interpretar que no se verifican las condiciones legales y reglamentarias.

- Principio de gratuidad. Esto es, prevé un acceso libre y gratuito a través de la web del Poder Judicial de la Nación.

- Principio de colaboración. La Acordada 12/2016 impone al actor el deber de denunciar las acciones colectivas interpuestas con identidad o similar objeto y tipo de proceso, con carácter de declaración jurada. En caso afirmativo, debe informarle al Tribunal causa judicial y estado procesal. Asimismo, impone el deber de consulta previa del registro y de informar al Tribunal el resultado de la búsqueda.

- Sistematización por el nombre de las partes, tribunal, materia, características del bien colectivo o derechos individuales homogéneos, composición de la clase.

- Respeto de la autonomía provincial en cuanto a las atribuciones reservadas de dictar sus códigos procesales y la legislación administrativa (artículos 75 inciso $12,121,122,123,125$ de la CN).

\subsection{Algunas consideraciones en torno al marco reglamentario del registro nacional de procesos colectivos y su funcionamiento}

La creación de este registro de procesos colectivos en la órbita del Poder Judicial nacional y su posterior reglamentación fue recibido con agrado por gran parte de la doctrina. Sin embargo, hay algunos aspectos que plantean interrogantes, otros que imponen una actividad innecesaria que tornan más complejo y burocrático el trámite y lagunas normativas que generan inseguridad jurídica.

Primero, el ámbito de aplicación en la Acordada 32/2014 se extendió a todo proceso colectivo, incluyendo el hábeas corpus colectivo. Sin embargo, inexplicablemente, la Acordada 12/2016 excluyó a aquellos que versan sobre cuestiones ambientales.

Esta exclusión ha sido criticada por la doctrina (Palacio de Caeiro y Junyent de Dutari, 2016; Salgado, 2016). No hay justificación alguna para su exclusión, ni siquiera la vigencia de Ley 25675, pues ni esta ni otras leyes (como la Ley de Defensa del Consumidor, que no ha sido excluida del alcance de la Acordada 
32/2014) son un obstáculo para la existencia de un registro. Todo lo contrario, la complejidad de la mayoría de las cuestiones ambientales, la masividad de sus daños y la posibilidad de extensión fuera de los límites de una provincia, la heterogeneidad de los intereses afectados (v.gr., afectación de los derechos de las comunidades aborígenes sobre su hábitat, además del tema ambiental) justifican su inclusión en el registro mencionado.

Segundo, la Acordada prevé una inscripción provisional de un proceso colectivo admitido por una resolución judicial cuando presenta defectos u omisiones. En efecto, el artículo 5 de la Acordada 32/2014 establece que el registrador debe verificar el cumplimiento de los recaudos reglamentarios en el plazo de dos días. En caso de formular observaciones, realiza una anotación provisoria, debiendo el tribunal subsanar las deficiencias en el plazo de treinta días.

Esta norma no prevé consecuencias jurídicas por la omisión de ese deber procesal o por su cumplimiento tardío. Eventualmente, podría suceder que esas deficiencias impidan verificar la identidad o conexidad del objeto con ulteriores procesos colectivos que pretendan inscribirse.

Tercero, se ha receptado el principio de inscripción única y de prevención. Ello implica que el registrador debe rechazar la anotación de nuevos procesos, comunicándoles la existencia del preexistente registrado.

¿Y si la resolución judicial que admitió un proceso como colectivo luego es dejada sin efecto por una cámara de apelaciones? ¿Y si alguna instancia del proceso colectivo caduca? ¿Cómo se identificarán los procesos cuyo registro fue rechazado por la existencia de aquel cuya inscripción luego es dejada sin efecto?

Creemos que es necesario dejar constancia marginal en el asiento registral del proceso registrado de la existencia de los otros procesos que fueron remitidos al tribunal que previno, su acumulación o no al primero, fecha de la comunicación y su rechazo.

Cuarto, la inscripción exige una actividad jurisdiccional previa (pedido de informes, remisión de expedientes, aclaraciones del registro, resolución de admisión formal del proceso colectivo y certificación de la clase), que deja abierta la puerta a la dilación del proceso (Palacio de Caeiro y Junyent de Dutari, 2016).

Esta dilación puede ser grave y terminar por desvirtuar el amparo colectivo. No se debe perder de vista que "el carácter ius publicista de la institución y su valor instrumental" para asegurar la vigencia cierta de los derechos constitucionales (Morello, 1995, p. 1216).

Lejos de ello, la Acordada 12/2016 exige innecesariamente actividades del juez y de abogados que pueden ser simplificadas y abreviadas. El artículo 2, in- 
ciso 2 d) y e) le impone al abogado del actor el deber de consulta del registro y posterior información del resultado al juez. También debe denunciar con carácter de declaración jurada si ha iniciado otras acciones judiciales con identidad de objeto que se refiera a esos intereses individuales homogéneos. Estos son requisitos de la demanda que versan sobre intereses individuales homogéneos.

Vemos que el Reglamento establece deberes procesales para el abogado con fundamento en el principio de colaboración y lealtad procesal. Sin embargo, introduce posteriormente un trámite innecesario, desconfiando de los profesionales del derecho. En efecto, una vez presentada la demanda, el juez debe recabar un informe del Registro. Este trámite y toda la actividad previa que conlleva (redacción del oficio pidiendo el informe, firma, remisión, recepción y contestación) podría suprimirse si se le exigiera al abogado no solamente la consulta del registro, sino también la solicitud de un informe extendido por la autoridad registral con vigencia por un plazo breve, que debería ser establecido en el reglamento.

En tal caso, si de ese informe surgiera la existencia de otro proceso colectivo o algún otro con conexidad, se le debería imponer al abogado la carga de presentarse en el primero (ya sea como adherente o coadyuvante, según el caso) o deducir la demanda por conexidad ante el juez interviniente en aquel.

Este informe registral, cuya presentación debe tener lugar juntamente con la demanda, es auspicioso en los amparos colectivos y también en las medidas cautelares.

Quinto, coincidimos con quienes sostienen que la legislación debe prever soluciones para los casos de coexistencia de dos o más pretensiones grupales sobre una misma cuestión (litispendencia por identidad), o en los supuestos de conexidad entre ellas (litispendencia por conexidad o acumulación de pretensiones) (Giannini et al., 2016).

Sexto, las acordadas comentadas mencionan la necesidad de coordinación con los registros provinciales. Sin embargo, han transcurrido siete años desde la Acordada 32/2014 y aún hay provincias que no han firmado convenios con esa finalidad ni han creado un registro de acciones colectivas, incluyendo al amparo colectivo.

\subsection{Los registros de procesos colectivos en el derecho público provincial}

En este aspecto, las provincias argentinas han sido pioneras, puesto que han creado registros provinciales de procesos colectivos en el ámbito local, en ciertos casos, anteriores al Registro nacional creado por la Acordada 32/2014. En- 
Marcela Sandra Molina | El amparo colectivo y el sistema registral de las acciones colectivas: a un lustro de las acordadas 32/2014 y 12/2016 ...

tre ellos, aquel creado y regulado por el Acuerdo Plenario 5/2005 de la Cámara de Apelaciones en lo Contencioso Administrativo de la Ciudad Autónoma de Buenos Aires, la Ley 2145 (esta última fue vetada por el Decreto 2018/06) y recientemente el artículo 261 Anexo A del Código Procesal para las relaciones de consumo, ${ }^{36}$ ambas de la Ciudad Autónoma de Buenos Aires. Asimismo, la Ley 13928 de la Provincia de Buenos Aires (modificada por la Ley 14192), la Ley 6053 de Corrientes (artículo 6), el artículo 658 del CPCyC de Tierra del Fuego y modificatorias, en los años 2005, 2010, 2011 y 2013, respectivamente.

Cabe aclarar que el Acuerdo Plenario 5/2005 de la Cámara de Apelaciones en lo Contencioso Administrativo y Tributario de la Ciudad Autónoma de Buenos Aires creó un registro exclusivo de amparos colectivos cuyo ámbito de aplicación fue ampliado y reglamentado por el Acuerdo plenario 4/2016.

También, la Ley 13928 de la Provincia de Buenos Aires, modificada por Ley 14192 (artículo 21), creó un registro de amparos colectivos que fue posteriormente absorbido por el registro de procesos colectivos, según dispuso la Acordada 3660/2013 de la Suprema Corte de Justicia de Buenos Aires, criterio normativo criticado por la doctrina local (Rizzi, 2013, pp. 1132-1145).

En el año 2014 (fecha en la que la CSJN dictó la Acordada 32), otras provincias también crearon registros con esa misma finalidad en el ámbito local. Entre ellas, las provincias de Santa Cruz (2015), ${ }^{37}$ Entre Ríos (2016), ${ }^{38}$ Salta (2016), ${ }^{39}$ Río Negro $(2017)^{40}$ y Córdoba (2018). ${ }^{41}$

Este registro recibe datos y recopila, ordena, sistematiza, brinda y publica toda la información vinculada al inicio y desarrollo de todo proceso colectivo. Todo ello con la finalidad de evitar el riesgo de sentencias contradictorias con efectos expansivos.

Todos los procesos colectivos deben inscribirse, tanto los que tienen por objeto bienes colectivos como intereses individuales homogéneos (excepto que involucre la libertad física), sean declarativos, preventivos, ordinarios o sumarísimos, incluyendo el amparo colectivo. Ya mencionamos que solamente crearon

36 Aprobado mediante la Ley 6407, sancionado 11/03/2021, publicado en el BO 19/03/2021.

37 Art.779 del Código Procesal Civil y Comercial, modificado por la Ley 3453 sancionada el 24/09/2015, publicada B.O 24/11/2015 y CCXX -02- 0406 dictada por el Tribunal Superior de Justicia el 29/06/2016.

38 Acuerdo general (reglamento) 33/16 del 17/11/16.

39 Ley 7968 sancionada el 01/12/16, publicada B.O 03/01/2017 y Acordada 12324 de la Corte Suprema de Justicia del 09/02/2017.

40 Acordada 13/2017 de la Suprema Corte de Justicia de Río Negro del 17/05/2017.

41 Acuerdo (reglamento) 1499-serie A del Superior Tribunal de Córdoba del 06/06/2018. 
registros de amparos colectivos las leyes de la provincia de Buenos Aires y de la Ciudad Autónoma de Buenos Aires en los años 2005 y 2008, respectivamente, pero posteriormente la legislación local amplió el ámbito de aplicación.

En general, las provincias han organizado estos registros sobre la base de cuatro principios, similares a aquellos receptados por el reglamento del Registro nacional:

- Principio de publicidad. Es el deber impuesto a los jueces, de comunicar al Registro el auto inicial que admite un proceso como colectivo y sus actos procesales posteriores (artículos 4 y 5 del Acuerdo General 33/2016 del Supremo Tribunal de Justicia de Entre Ríos (STJER); artículos 5 y 6 de la Ley 7968 de Salta; artículo 6 de la Ley 6053 de Corrientes; artículo 3 del Reglamento de Procesos colectivos aprobado por la Acordada 3660/2013 de la Suprema Corte de Justicia de Buenos Aires; Anexo I del Acuerdo 26/2014 de la Suprema Corte de Justicia de Corrientes; Acordada 13/2017 de Río Negro).

- Principio de prevención.

- Principio de gratuidad, esto es, acceso en forma libre, sencilla y gratuita (artículo 9 del Reglamento aprobado por la Acordada 3660/2013 de la SCJ; artículo 21 de la Ley 13928 de la Provincia de Buenos Aires modificada por la Ley 14192; artículo 9 del Anexo I del Acuerdo General 33/2016 de la STJ Entre Ríos; artículos 1 y 10 de la Ley 7968 de Salta; artículo 5, Anexo I del Acuerdo 26/2014 de la SJC Corrientes).

- Principio de colaboración. Las normas locales requieren la colaboración del actor en la identificación de procesos ya iniciados, ya sea mediante una declaración jurada de no haber iniciado una acción judicial con idéntico o similar objeto (en caso afirmativo, informando el tribunal de origen causa judicial y estado procesal) o mediante la presentación de un informe digital del sistema informático.

\subsection{Algunas reflexiones sobre los registros de procesos colectivos provinciales. Su necesaria armonización y coordinación con el registro nacional}

En la legislación procesal provincial existe coincidencia en los principios rectores del sistema registral (acceso público, gratuidad, sistema de prevención), pero se presentan algunos vacíos normativos e interrogantes similares a los mencionados en relación con el Registro nacional, por lo que nos remitimos a lo allí expuesto.

Además, se advierten algunos aspectos específicos en su instrumentación que también pueden afectar la sencillez y agilidad que exige el amparo colectivo. 
Marcela Sandra Molina | El amparo colectivo y el sistema registral de las acciones colectivas: a un lustro de las acordadas 32/2014 y 12/2016 ...

Primero, en estos registros se asientan todos los procesos colectivos, declarativos o preventivos, ordinarios o sumarísimos.

Debe tenerse en cuenta que en las provincias se destacan cuantitativamente los amparos colectivos, especialmente los amparos ambientales. ${ }^{42}$ Esta realidad nos lleva a las siguientes reflexiones.

Por un lado, se advierte una diferencia sustancial en la regulación nacional y provincial de los registros en materia ambiental, lo que es inconveniente para cumplir con la finalidad de su creación. Las normas locales incluyen las acciones sobre materia ambiental. En cambio, la Acordada 12/2016 de la CSJN los excluyó del registro nacional.

Por otro lado, insistimos en que el amparo colectivo exige un trámite expedito y rápido que no puede ser distorsionado con el trámite de registración. Es decir, debe armonizarse el principio de publicidad registral con el principio de celeridad e inmediatez que exigen estas acciones de rango constitucional.

En este sentido, destacamos que algunas normas provinciales prevén una categorización según el tipo de proceso y materia. Las normas reglamentarias del Registro de procesos colectivos de Córdoba y de la provincia de Buenos Aires han innovado en este aspecto, aunque han adoptado distintos criterios de clasificación, lo que facilita el establecimiento de normas específicas para los amparos colectivos. El Reglamento 1491/2018 Serie A de Córdoba ha incorporado las siguientes categorías: 1) amparo colectivo; 2) acción colectiva; esta, a su vez, se subdivide en: abreviado y ordinario; y 3) acción declarativa de inconstitucionalidad. Por su parte, el artículo 8 del Reglamento aprobado por la Acordada 3660/2013 de la Provincia de Buenos Aires los ha categorizado en: amparos de incidencia colectiva y otros procesos de incidencia colectiva.

Segundo, no siempre es fácil dilucidar la naturaleza colectiva de una acción en la que se invocan derechos individuales homogéneos, tramitada como un proceso individual. En algún caso, los jueces de primera y segunda instancia admitieron solamente la acción individual, pero la Corte provincial admitió

42 A título ilustrativo, en el Registro de Procesos Colectivos de Río Negro se han registrado 74 procesos desde su creación por la Acordada 13/2017, de los cuales 72 son amparos colectivos (52 amparos ambientales) (disponible en: http://servicios.jusrionegro.gov.ar/inicio/web/). En el Registro de la Ciudad Autónoma de Buenos Aires, durante el año 2020, se anotaron 79 procesos colectivos, de los cuales 64 fueron amparos colectivos (disponible en: https://consejo.jusbaires.gob.ar/institucional/registro-de-procesos-colectivos/registros; listado por orden cronológico, número de expediente, carátula, objeto, juzgado y fecha inicio). En el Registro de la Provincia de Buenos Aires, durante el año 2020, ingresaron 78 causas (22 amparos colectivos) (disponible en: http://rpc.scba.gov.ar/ BuscarCausas.aspx). 
parcialmente la acción colectiva. ${ }^{43}$ De conformidad con las reglas generales sobre competencia, acumulación de procesos y el principio de preclusión, en esos casos no podría remitirse ese proceso al juez que previno. Por tanto, queda latente el riesgo de sentencias contradictorias con efectos expansivos.

Tercero, no es fácil investigar los procesos colectivos en trámite con identidad de objeto y causa cuando no se tiene el nombre de las partes. Muchos registros son incompletos porque no detallan el objeto del proceso ni otros datos relevantes (fecha del hecho, estado del trámite, etc.); en otros, se enumeran los procesos con indicación de datos sin un criterio de ordenación o simplemente por orden cronológico. Es conveniente usar palabras clave por tema y tesauro, o también por años y/o fecha del hecho, incluso establecer links para conocer el contenido de las resoluciones judiciales dictadas en el proceso.

Cuarto, las leyes provinciales establecen la obligatoriedad de remisión de datos al registro (artículos 4 y 5 del Acuerdo General 33/2016 del STJER, artículos 5 y 6 de la Ley 7968); pero algunas normas no establecen plazo dentro del cual debe remitirse ni el plazo en el que debe ser procesada y registrada la información por el órgano competente. ${ }^{44}$

También hay diversidad de medios de remisión de información y comunicación. Algunos prevén la comunicación electrónica (artículo 6 del Anexo I del Acuerdo General 33/2016 del STJER); otras, mediante oficio (Acordada 12324 de la Corte de Justicia de Salta); otras les asignan a las autoridades del Poder Judicial establecer el medio adecuado (artículo 7 de la Ley 7968 de Salta) o el soporte papel (artículo 5 del Reglamento de procesos colectivos aprobado por la Acordada 3660/2013 de la SCJ de Buenos Aires, aunque también prevé la posibilidad de remisión por correo electrónico). Otras exigen un informe sin aclarar el medio de comunicación (artículos 3 y 13 del Anexo II del Acuerdo General 33/2016 del STJER; artículo 6 de la Ley 6053 de Corrientes).

Quinto, hay diferencias de criterios en cuanto a la forma de acceso al público. En algunos, se instrumentó a través del sistema informático (punto VI de la Acordada 12324 de la Corte de Justicia de Salta; artículo 9 del Reglamento

43 Suprema Corte de Justicia de Mendoza, Sala 1, Sosa Beatriz c/AMX Argentina, 27/07/2012. Disponible en: http://www.jus.mendoza.gov.ar.

44 Pocas leyes prevén plazo. El artículo 8 de la Ley 7968 y la Acordada 12324 de la Corte de Justicia de Salta establecen un plazo de dos días para asentar la inscripción una vez recibida la información por el órgano respectivo; el mismo plazo se le da al órgano judicial para remitir la información al registro y para expedir el informe sobre procesos registrados. Otras prevén un plazo de cinco días (Acordada 04/06/2016 del STJ de Santa Cruz y el artículo 7 del Reglamento aprobado por la Acordada 3660/2013 de la SCJ de Buenos Aires), siendo este muy extenso para un amparo colectivo. 
Marcela Sandra Molina | El amparo colectivo y el sistema registral de las acciones colectivas: a un lustro de las acordadas 32/2014 y 12/2016 ...

aprobado por la Acordada 3660/2013 de la SCJ de Buenos Aires); en otros, a través de informes (artículo 11 del Reglamento aprobado por la Acordada 3660 de la SCJ de Buenos Aires). Otras normas locales prevén regulaciones muy escuetas y generales. Finalmente, en algunas provincias se ha instrumentado un régimen de expedición de certificados (artículo 779 del CPCyC de Santa Cruz).

\section{La competencia en las acciones colectivas}

Un tema que genera interrogantes es la competencia federal en amparos colectivos y demás acciones colectivas con alcances en más de una jurisdicción (Perez Hazaña, 2017, p. 957), o actores dentro de una misma clase con domicilio en distintas provincias, especialmente por distintas interpretaciones sobre el concepto de "distinto domicilio" que menciona el artículo 116 de la CN.

Como señala Lorenzetti (2012), no coincide el problema (el hecho común) con la jurisdicción provincial, lo que puede generar conflictos de competencias y de superposición de procesos. Además, el proceso colectivo es un proceso policéntrico, en el que hay distintos tipos de interés (conflicto de intereses colectivos), no solamente actor y demandado (v.gr., cuestión ambiental, patrimonio cultural y derechos de una comunidad aborigen).

Por eso no es fácil discernir la competencia en las acciones colectivas por la multiplicidad e indeterminación (o muy difícil determinación) de los titulares de los derechos de incidencia colectiva y su carácter policéntrico. Incluso, en algunos casos puede ser difícil establecer a priori los efectos espaciales de un mismo hecho ambiental, cultural, de discriminación, etc. También es frecuente la expansión territorial interjurisdiccional de la afectación de derechos e intereses (Giannini et al., 2016), tornándose más compleja la dilucidación de la competencia judicial en los Estados federales como Argentina.

Por tanto, debe dilucidarse la competencia federal o provincial y, aun dentro de cada jurisdicción, la competencia por razón del territorio y por la materia.

La competencia federal se limita a los supuestos enumerados en los artículos 116 y 117 de la CN por tratarse de un fuero de excepción y de interpretación restrictiva. Entre ellos, pueden incluirse los conflictos interjurisdiccionales.

En materia ambiental, el fallo in re Mendoza, Beatriz $z^{45}$ la CSJN dijo que

el artículo $7^{\circ}$ de la ley 25.675 prevé la competencia federal cuando se trata de

45 Corte Suprema de Justicia de la Nación, Mendoza, Beatriz c/Estado Nacional, 20/06/2006, Fallos: $329: 2316$. 
la degradación o contaminación de recursos ambientales interjurisdiccionales, hipótesis que se verifica al estar involucradas más de una jurisdicción estatal, y cuando las pretensiones tienen en mira ese presupuesto atributivo de competencia -la degradación o contaminación de recursos ambientales- al perseguir la recomposición y el resarcimiento del daño de incidencia colectiva, que es el único reglado y alcanzado por este estatuto especial...

\title{
El máximo Tribunal explicitó esa regla in re Di Giano, ${ }^{46}$ en la que apuntó:
}

La cuestión relativa al impacto ambiental no puede obstar a la determinación de la competencia provincial si, según lo establece el art. 7 de la Ley 25.675 (de política ambiental nacional) su aplicación es de conocimiento prioritario de los tribunales ordinarios, según el territorio, la materia o las personas, y sólo caber apartarse de esa regla cuando el acto, omisión o situación generada provoque, efectivamente, degradación o contaminación en recursos ambientales de naturaleza interjurisdiccional.

Este criterio fue reiterado in re Benzrihen. ${ }^{47}$

En relación con las acciones colectivas relativas a derechos individuales homogéneos en materia de consumo, el Superior Tribunal dijo:

\begin{abstract}
Si bien el objeto de la pretensión se refiere a un negocio regulado por el derecho común (al tratarse de una medida autosatisfactiva, en la que se invocan intereses difusos de los consumidores, tendiente a que se restituyan los vínculos por donde circula la parte más importante del tráfico de Internet en el país) cuyo juzgamiento, en principio, corresponde a las jurisdicciones ordinarias locales (art. 75 inc. $12 \mathrm{CN}$ ), no es aplicable la regla general que determina que los gobiernos provinciales y la Municipalidad de Buenos Aires actúan como autoridades locales de aplicación (art. 64 Ley 24.240), pues no están afectados sólo intereses locales... ${ }^{48}$
\end{abstract}

En la causa judicial Consumidores Financieros, ${ }^{49}$ la actora había promovido diferentes acciones judiciales con pretensiones idénticas en contra de las entidades bancarias que cobrarían una comisión por riesgo contingente. La CSJN

46 Corte Suprema de Justicia de la Nación, Di Giano, Isabel 05/04/2018, Fallos: 341:324.

47 Corte Suprema de Justicia de la Nación, Benzrihen c/Industrias Magromer Cueros y Pieles SA, 21/09/2010, Fallos: 333:1808.

48 Corte Suprema de Justicia de la Nación, Asociación Vecinal de Belgrano, 23/12/2004, Fallos: 327:6043.

49 Corte Suprema de Justicia de la Nación, Consumidores Financieros c/Banco Itaú Buen Ayre Argentina, 10/07/2018, Fallos: 341:739. 
consideró que debían radicarse ante el tribunal que conocen en pleitos con objeto idéntico o similar que presenta mayor grado de avance, descartando otros criterios como el sorteo o notificación de la demanda.

En síntesis, podemos sentar como regla general que corresponde la competencia de los tribunales ordinarios por razón del territorio o las personas; solamente cabe apartarse de esa regla cuando el acto, omisión o situación generada sea interjurisdiccional o, en los otros casos, enumerados en los artículos 116 y 117 de la CN.

Sin embargo, puede suceder que el juez que previno sea un juez provincial, pero finalmente la causa judicial pasa a ser de competencia federal cuando se identifica un conflicto interjurisdiccional y hay procesos iniciados en otras provincias. En este último caso, no podría aplicarse la regla de la competencia del juez provincial que previno cuando las partes no han prorrogado la jurisdicción.

En efecto, la competencia atribuida a los tribunales federales es improrrogable según lo dispone el artículo 1 del CPCCN, salvo por razones de vecindad. Excepcionalmente puede ser prorrogada la competencia territorial por las partes en asuntos exclusivamente patrimoniales, ya sea en forma expresa o tácita. La prórroga operará si surgiera de un convenio escrito mediante el cual los interesados manifiesten explícitamente su decisión de someterse a la competencia del juez a quien acuden. También implica prórroga de la competencia por el actor, por el hecho de entablar la demanda en un tribunal provincial.

En definitiva, el artículo 5 del CPCyCN establece las reglas para determinar la competencia de los tribunales en caso de derechos y obligaciones individuales (reales o personales), pero nada dice sobre los derechos e intereses difusos; menos aún sobre los amparos colectivos. Existe una laguna jurídica esencial que exige la sanción de una ley, cuya integración con las normas procesales vigentes aplicables por analogía no siempre conduce a soluciones razonables.

\section{Conclusiones}

El Congreso Nacional no ha reglamentado el amparo colectivo hasta la fecha, aun cuando se han presentado numerosos proyectos de ley con distintos alcances.

La regulación del amparo colectivo es un deber constitucional por cuanto debe preverse una vía procesal adecuada para la protección de los derechos de incidencia colectiva receptados en los artículos 41 y 42 de la Constitución Nacional y los tratados internacionales de derechos humanos, enumerados en el artículo 75, inciso 22. El régimen general de la Ley 16981 no se adapta a la naturaleza colectiva de aquel, dejando amplios vacíos normativos. 
La inexistencia de una regulación nacional específica sobre amparos colectivos, en especial frente a la inexistencia de un régimen general de acciones colectivas, genera inseguridad jurídica en su tramitación, especialmente en torno a la litispendencia y el riesgo de proliferación de procesos con idéntico objeto en distintas jurisdicciones. Ello exige sistemas de publicidad para identificar rápida y oportunamente las acciones interpuestas, los procesos con idéntico o similar objeto, causa y sujetos y tipo de proceso (ordinario, sumarísimos, cautelares, etc.). Entre ellos, el registro de acciones colectivas se erige como un sistema de publicidad que produce efectos jurídicos, como el deber de remitir los procesos judiciales al juez que previno.

Esta necesidad es aún mayor en los amparos colectivos, por la brevedad de sus plazos y urgencia en la resolución de los conflictos para restablecer el derecho fundamental vulnerado.

Resulta inobjetable la organización de los registros sobre la base de los principios de acceso público y libre, registro único y los principios de prevención y colaboración. No obstante, consideramos que debe suprimir trámites innecesarios que tornan burocrático el proceso de registración y además que deben establecerse soluciones en las lagunas normativas.

En definitiva, creemos que la organización debe regularse conforme a esos pilares y de acuerdo con el principio de sencillez, economía procesal, celeridad, completitud y generalidad, sin perder de vista que involucra aspectos técnico-registrales y administrativos.

Según el principio de generalidad, debe imponerse la obligación de comunicar y registrar todas las acciones colectivas, cualquiera sea el tipo de proceso y materia, incluyendo las cuestiones ambientales. La complejidad de la mayoría de las cuestiones ambientales, la masividad de sus daños y la posibilidad de extensión fuera de los límites de una provincia, la heterogeneidad de los intereses y su carácter policéntrico justifican la inclusión de estos procesos colectivos en el registro.

Por su parte, el principio de completitud prevé la sistematización múltiple por el nombre de las partes, tribunal y circunscripción, materia y tipo de proceso. El asiento registral debe incluir datos básicos del proceso: número de expediente, carátula, sujetos y sus abogados, objeto bien detallado -hecho concreto, fecha del hecho, breve relación de la plataforma fáctica-, tribunal, fecha de inicio y terminación, estado del proceso, descripción de la clase, características del bien colectivo o derechos individuales homogéneos, actos procesales relevantes, especialmente la sentencia indicando si hizo lugar o rechazó la de- 
manda. Incluso, deberían mencionarse links que permitan el acceso directo y rápido a la documentación esencial. Asimismo, debería:

- Incluir una sección referida a la parte actora (discriminando, según sea el afectado, asociaciones civiles, Defensor del Pueblo y demás entes estatales cuya legitimación anómala ha sido prevista en la legislación provincial, indicando su domicilio real, social y legal, respectivamente; también el domicilio real de la demandada).

- Establecer consecuencias por el vencimiento de la inscripción provisoria prevista por el artículo 5 de la Acordada 32/2014, por incumplimiento de esta subsanación o cumplimiento tardío de errores, deficiencias u oscuridad.

- Exigir la anotación -aunque sea como nota marginal- de la existencia de los otros procesos colectivos que fueron remitidos al tribunal que previno, su acumulación o no al primer proceso, fecha de la comunicación y orden judicial de inscripción y su rechazo. Además, debería proveer información sobre los conflictos de competencia que se han planteado e indicar el juzgado donde quedó radicada la causa judicial.

Con respecto al principio de sencillez y economía procesal, se podría regular la expedición de un informe digital otorgado por el registrador, superador del informe del abogado con carácter de declaración jurada sobre el resultado de la búsqueda en el registro. Se le debe imponer al abogado el deber procesal de presentar este informe junto con la demanda, suprimiendo la etapa de la consulta e informe posterior solicitado por el Tribunal, así como la actividad previa (redacción y firma del oficio, remisión y recepción, contestación del informe, etc.).

En cuanto a la celeridad, las normas de organización del registro deberían prever plazos breves y perentorios. Este principio tiene especial relevancia en los amparos colectivos por tratarse de una garantía constitucional que debe ser regulada como una vía procesal expedita.

Finalmente, hay aspectos que no pueden ser resueltos por una acordada de la Corte Suprema, pues son de competencia exclusiva del Poder Legislativo, como la modificación de la competencia prevista en el Código Procesal o también la modificación o limitación de la legitimación, etc. 


\section{Bibliografía}

Abraham, H. J. (1993). The Judicial Process. Oxford University Press.

Azar, J. (2015). Los derechos de incidencia colectiva en el Proyecto de Código Civil y Comercial de la Nación. Comentario de una supresión. Revista Derecho Privado, 1(2), 241-280. http:// www.pensamientocivil.com.ar/system/files/2015/01/Doctrina456.pdf.

Barbosa Moreira, C. (1992). La iniciativa en la defensa judicial de los intereses difusos y colectivos: un aspecto de la experiencia brasileña. Comunicación en las XIII Jornadas Iberoamericanas de Derecho Procesal. Cuernavaca, México. http://publicacionesicdp.com/index.php/Revistas-icdp/article/view/269.

Barra, R. (1994). La acción de amparo en la constitución reformada: la legitimación para obrar. La Ley, 1994-E, 1087-1097.

Basterra, M. (2013). El amparo ambiental. Revista Jurisprudencia Argentina, 2013-IV.

Bianchi, A. (1998). Las acciones de clase. Una solución a los problemas procesales de la legitimación colectiva. Editorial Ábaco.

Bianchi, A. (2003). Control de Constitucionalidad (Tomo II). Editorial Ábaco.

Bidart Campos, G. (1995). Tratado Elemental de Derecho Constitucional Argentino (Tomo IV). Ediar.

Bidart Campos, G. (2004). Compendio de Derecho Constitucional. Ediar.

Bidart Campos, G. (2006). Manual de la Constitución Reformada (Tomo II). Ediar.

Bogart, W., Kalajdzic, A. y Matthew, I. (2007). Class Actions in Canada: A National Procedure in a Multi-Jurisdictional Society? The Globalization of Class Actions Conference. Universidad de Oxford.

Carnota, W. (2012). Las acciones de clase: desde los estados unidos a la argentina. Anuario Iberoamericano de Justicia Constitucional, (16), 93-106.

Cassagne, J. C. (1995). Sobre la Protección Ambiental. La Ley, 1995-E, 1217-1225.

Cassagne, J. C. (2000). Acerca de la eficacia erga omnes de las sentencias anulatorias de reglamentos. El Derecho, 185, 703-713.

D’Argenio, I. (2015). Un lamentable retroceso. La Ley, 2015-F, 295-300.

Díaz, S. A. (2001). Acción de amparo. La Ley.

Didier F. (Jr.) y Zaneti, H. (Jr.). (2017). Las acciones colectivas y el enjuiciamiento de casos repetitivos: dos tipos de proceso colectivo en el Derecho brasileño. International Journal of Procedural Law, 7(2), 266-275.

Ekmekdjian, M. A. (1999). La protección judicial de los intereses difusos en el derecho constitucional argentino. Anuario Iberoamericano de Justicia Constitucional, (3), 1-25.

Falcón, E. (2007). Tratado de Derecho Procesal Civil y Comercial (Tomo VI). Rubinzal Culzoni.

Gauffin, A. (19 de junio de 2015). Registro Público de Procesos Colectivos. Poder Judicial de la Provincia de Salta. http://www.escuelamagistratura.gov.ar/opinion-justicia-salta.php?IdOpinion $=74$.

Gelli, M. A. (2004). Constitución de la Nación Argentina Comentada y Concordada (2a ed.). La Ley. Giannini, J., Salgado, J. M. y Verbic, F. (2017). Anteproyecto de ley de procesos colectivos. Revista de Derecho Procesal, 2017, 1-10.

Giannini, L., Pérez Hazaña, A., Kalafatich, C., Rusconi, D., Salgado, J., Sucunza, M., Tau, M., Ucín, C. y Verbic, F. (30 de junio de 2016). Propuesta de bases para la discusión de un proyecto 
Marcela Sandra Molina | El amparo colectivo y el sistema registral de las acciones colectivas: a un lustro de las acordadas 32/2014 y 12/2016 ...

de ley que regule los procesos colectivos. Ministerio de Justicia y Derechos Humanos de la Nación Programa Justicia 2020. https://www.academia.edu/28282751/Propuesta_de_bases_ para_la_discusi\%C3\%B3n_de_un_proyecto_de_ley_que_regule_los_procesos_colectivos.

Gidi, A. (2004). Las acciones colectivas en Estados Unidos. Direito e Sociedade, 3(1), 17-150.

Gozaíni, O. (2015). Creación del Registro de acciones colectivas. La Ley T²015-A, 554-561.

Guayacán Ortiz, J. C. (2005). La acción popular, la acción de grupo y las acciones colectivas. Comparación de algunos tópicos entre el ordenamiento colombiano y el Anteproyecto de Código Modelo de procesos colectivos para Iberoamérica. Revista de Derecho Privado, (9), $35-56$.

Jimenez Jiménez, E. P. (2005). El amparo colectivo. En Manili, P. (Coord.), Derecho procesal constitucional (pp. 79-85). Editorial Universidad.

López Alfonsín, M., Berra, E. y Sparaccarotella, S. (2018). La incorporación de los derechos de incidencia colectiva en el proceso judicial. Jusbaires.

Lorenzetti, R. L. (2010). Justicia colectiva. Rubinzal Culzoni.

Lorenzetti, R. L. (2012). Procesos colectivos y derechos constitucionales. I Conferencia Internacional de la Asociación Internacional de Derecho Procesal y del Instituto Iberoamericano de Derecho Procesal y XXIII Jornadas Iberoamericanas de Derecho Procesal. Buenos Aires, Argentina, 6 y 9 de junio. https://www.cij.gov.ar/nota-9319-Se-realizaron-en-la-Ciudad-de-Buenos-Aires-las-XXIII-Jornadas-Iberoamericanas-de-Derecho-Procesal.html.

Mairal, H. (1998). Los efectos de las sentencias de la Corte Suprema de Justicia de la Nación. El Derecho, 177, 795-805.

Marianello, P. (2011). El amparo en Argentina. Evolución, rasgos y características especiales. Revista IUS, 5(27).

Morello, A. (1995). Posibilidades y limitaciones del amparo. El Derecho, 165, 1216-1219.

Neira Pena, A. M. (2019). Tutela colectiva y principios procesales. Las necesarias limitaciones del principio dispositivo en los procesos colectivos. Ius et Praxis, 25(1), 195-250.

Olmos Sonntag, M. (s.f.). El amparo como instrumento de control. http://www.derecho.uba.ar/ docentes/pdf/el-control-de-la-actividad-estatal-ii/cae2-olmos-sonntag.pdf.

Palacio de Caeiro, S. y Junyent de Dutari, P. (2016). El amparo colectivo y la reciente Acordada de la Corte Suprema. La Ley, 2016-D, 691-699.

Perez Hazaña, A. (2017). ¿Competencia federal o local? El caso de las acciones colectivas multi jurisdiccionales. Revista de Derecho Comercial y de las Obligaciones, 285, 957-974.

Quiroga Lavié, H. (1996). Actualidad en la jurisprudencia sobre amparo. La Ley, 1996-E, 10571065.

Quiroga Lavié, H. (1998). Amparo colectivo. Rubinzal Culzoni.

Quiroga Lavié, H. (2012). Las nuevas circunstancias del amparo colectivo. Protección del medio ambiente. Revista Derecho y Ciencias Sociales, (6), 169-181.

Rizzi, G. (2013). La Acordada N³660/2013 de la SCBA o la inconveniencia de regular los procesos colectivos en una ley de amparo. La Ley, 2013-F, 1132-1145.

Rosenberg, M. (2016). Programa Interamericano de Capacitación sobre la Reforma a la Justicia Civil en América Latina. Centro de Estudios de Justicia para América.

Sabsay, D. A. (1997). El Amparo ¿colectivo consagrado por la reforma constitucional del 1994. Cuadernos de Análisis Jurídico, (7), serie publicaciones especiales, 387-405. 
Sabsay, D. A. (2000). El amparo como garantía para el acceso a la jurisdicción en defensa de los derechos humanos. Revista de Derecho Procesal, (5), 23-47.

Sagües, N. (2004). El amparo ambiental. La Ley, 2004-D, 1194-1199.

Sagües, N. (2013). El amparo como acción de clase (caso Halabi). Astrea.

Sagües, N. (2016). La acción de clase se despega del amparo. Revista Digital, (211).

Salgado, J. M. (2010). Amparo colectivo. En Falcón, E. (Dir.), Tratado de Derecho Procesal Constitucional (Tomo II, pp. 205-383). Rubinzal Culzoni.

Salgado, J. M. (2016). La Corte legisla sobre los procesos colectivos. La Ley, 2016-C, 626-631.

Timpanaro, A. R. (2012). Acciones de clase. Consideraciones respecto a su régimen procesal ante la ausencia de una ley que lo reglamente. En Bruno Dos Santos, M. (Dir.), Una mirada desde el fuero contencioso administrativo federal sobre el Derecho Procesal Administrativo (1 ${ }^{\text {a }}$ ed., pp. 289-303). Buenos Aires.

Verbic, F. (2012). Tutela colectiva de derechos en Argentina. Revista de Derecho Procesal, (número extraordinario), $80-87$.

Verbic, F. (15 de abril de 2015). Publicidad y notificaciones en los procesos colectivos de consumo. Diario La Ley. https://cjprocesalistas.com.ar/publicaciones/105-publicidad-y-notificaciones-en-los-procesos-colectivos-de-consumo.

Verbic, F. (5 de abril 2017). Procesos colectivos inscriptos en el Registro Público que administra la CSJN: un reciente relevamiento no oficial arroja como resultado la existencia de más de 900 expedientes anotados. Class Actions en Argentina. https://classactionsargentina.com/2017/10/05/procesos-colectivos-inscriptos-en-el-registro-publico-que-administra-la-csjn-un-reciente-relevamiento-no-oficial-arroja-como-resultado-la-existencia-de-mas-de-900-expedientes-anotados-fed/.

Vergara, N. (27 de noviembre de 2011). Las acciones colectivas en el derecho comparado. Sistema Argentino de Información Juridica (SAIJ). http://www.saij.gob.ar/doctrina/dacf110149-vergara-las_acciones_colectivas_en.htm.

\section{Jurisprudencia citada}

\section{Argentina}

\section{Corte Suprema de Justicia de la Nación}

Asociación Benghalensis c/Ministerio de Salud de la Nación, 01/06/2000, Fallos: 323:1339. Asociación Vecinal de Belgrano, 23/12/2004, Fallos: 327:6043.

Benzrihen c/Industrias Magromer Cueros y Pieles SA, 21/09/2010, Fallos: 333:1808.

Consumidores Financieros c/Banco Itaú Buen Ayre Argentina, 24/06/2014, Fallos: 337:753.

Consumidores Financieros c/Banco Itaú Buen Ayre Argentina, 10/07/2018, Fallos: 341:739.

Consumidores Financieros c/La Meridional Cía de Seguros, 24/06/2014, Fallos: 337:762.

Di Giano, Iris Isabel, 05/04/2018, Fallos: 341:324.

Defensor del Pueblo de la Nación c/Estado Nacional, 26/06/2007, Fallos: 330:2800.

Halabi, Ernesto, 04/03/2009, Fallos: 332:111.

Mendoza, Beatriz c/Estado Nacional, 20/06/2006, Fallos: 329:2316.

Mendoza, Beatriz c/Estado Nacional, 30/08/2006, Fallos: 329:3528.

Municipalidad de Berazategui c/Cablevisión S.A., 23/09/2014, Fallos: 337:1024. 
Marcela Sandra Molina | El amparo colectivo y el sistema registral de las acciones colectivas: a un lustro de las acordadas 32/2014 y 12/2016 ...

PADEC c/SWISS MEDICAL S.A., 21/08/2013, Fallos: 336:1236.

Pla, Hugo c/Provincia de Chubut, 13/05/2008, Fallos: 331:1243.

Portal de Belén Asoc. Civil c/Ministerio de Salud de la Nación, 05/03/2002, Fallos: 325:292.

\section{Otros tribunales}

Cámara Nacional Comercial, sala C, ASOCIACIÓN PROTECCIÓN CONSUMIDORES DEL MERCADO COMUN DEL SUR-PROCONSUMER c/COTO SA, 06/11/2019.

Cámara Nacional Comercial, sala D, PROCONSUMER c/LAN Argentina SA s/sumarísimo, $12 / 12 / 2017$

Cámara Nacional Comercial, sala F, Consumidores Financieros Asociación Civil c/Liderar Compañía de Seguros SA, 22/08/2013.

Suprema Corte de Justicia de Mendoza, Egea c/Dirección de Vias y Medios de Transporte, 07/02/2011, LS. 422, 157.

Suprema Corte de Justicia de Mendoza, Sala 1, Sosa Beatriz c/AMX Argentina, 27/07/2012. LS 440-155.

\section{Canadá}

King Ë Dawson v. el Gobierno de P.E.I, 2020. 